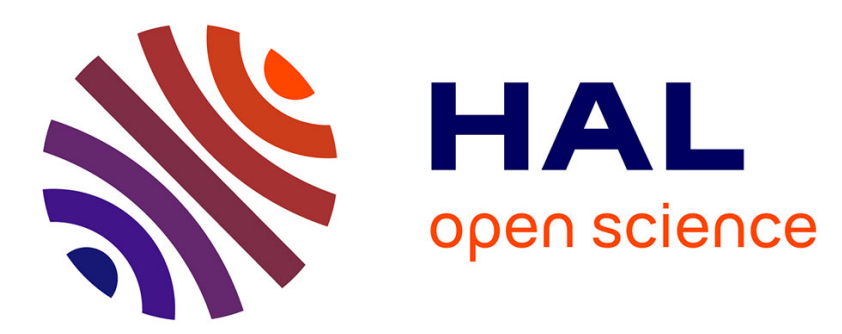

\title{
A sequential model for disaggregating near-surface soil moisture observations using multi-resolution thermal sensors
}

\author{
Olivier Merlin, Al Bitar Ahmad, J P. Walker, Yann H. Kerr
}

\section{To cite this version:}

Olivier Merlin, Al Bitar Ahmad, J P. Walker, Yann H. Kerr. A sequential model for disaggregating near-surface soil moisture observations using multi-resolution thermal sensors. Remote Sensing of Environment, 2009, pp.RSE-07453; No of Pages 10. 10.1016/j.rse.2009.06.012 . ird-00403130

\section{HAL Id: ird-00403130 \\ https://hal.ird.fr/ird-00403130}

Submitted on 9 Jul 2009

HAL is a multi-disciplinary open access archive for the deposit and dissemination of scientific research documents, whether they are published or not. The documents may come from teaching and research institutions in France or abroad, or from public or private research centers.
L'archive ouverte pluridisciplinaire HAL, est destinée au dépôt et à la diffusion de documents scientifiques de niveau recherche, publiés ou non, émanant des établissements d'enseignement et de recherche français ou étrangers, des laboratoires publics ou privés. 


\title{
1 A sequential model for disaggregating near-surface soil moisture observations using multi-resolution thermal sensors
}

\author{
Olivier Merlin ${ }^{\mathrm{a}, *}$, Ahmad Al Bitar ${ }^{\mathrm{a}}$, Jeffrey P. Walker ${ }^{\mathrm{b}}$, Yann Kerr ${ }^{\mathrm{a}}$ \\ a Centre d'Etudes Spatiales de la Biosphère (CESBIO), Toulouse, France \\ b Civil and Environmental Engineering, The University of Melbourne, Australia
}

\section{A R T I C L E I N F O}

\section{Article history:}

Received 9 April 2009

Received in revised form 16 June 2009

Accepted 20 June 2009

Available online $\mathrm{xxxx}$

\section{Keywords:}

Disaggregation

Soil moisture

Fractal

Scaling

Multi-sensor

NAFE

SMOS

MODIS

ASTER

\section{A B S T R A C T}

A sequential model is developed to disaggregate microwave-derived soil moisture from $40 \mathrm{~km}$ to $4 \mathrm{~km} 26$ resolution using MODIS (Moderate Imaging Spectroradiometer) data and subsequently from $4 \mathrm{~km}$ to $500 \mathrm{~m} 27$ resolution using ASTER (Advanced Scanning Thermal Emission and Reflection Radiometer) data. The $1 \mathrm{~km} 28$ resolution airborne data collected during the three-week National Airborne Field Experiment 200629 (NAFE'06) are used to simulate the $40 \mathrm{~km}$ pixels, and a thermal-based disaggregation algorithm is applied 30 using $1 \mathrm{~km}$ resolution MODIS and $100 \mathrm{~m}$ resolution ASTER data. The downscaled soil moisture data are 31 subsequently evaluated using a combination of airborne and in situ soil moisture measurements. A key step 32 in the procedure is to identify an optimal downscaling resolution in terms of disaggregation accuracy and 33 sub-pixel soil moisture variability. Very consistent optimal downscaling resolutions are obtained for MODIS 34 aboard Terra, MODIS aboard Aqua and ASTER, which are 4 to 5 times the thermal sensor resolution. The root 35 mean square error between the $500 \mathrm{~m}$ resolution sequentially disaggregated and ground-measured soil 36 moisture is $0.062 \mathrm{vol}$./vol. with a bias of $-0.045 \mathrm{vol}$. $/ \mathrm{vol}$. and values ranging from 0.08 to $0.40 \mathrm{Nol}$. $/ \mathrm{vol}$. 37

(c) 2009 Elsevier Inc. All rights reserved. 38

\footnotetext{
* Corresponding author.

E-mail address: olivier.merlin@cesbio.cnes.fr (O. Merlin).
}

Downscaling methodologies are therefore needed to improve the 61 spatial resolution of passive microwave-derived soil moisture. To 62 understand how soil moisture scales, the spatial structure of soil 63 moisture fields has been statistically described using experimental 64 data sets aggregated at a range of resolutions. Those studies (e.g. 65 Rodriguez-Iturbe et al., 1995; Das \& Mohanty, 2008) conducted over 66 different sites and using either remotely sensed or ground-based data, 67 conclude that soil moisture behaves as a fractal -i.e. follows a power 68 law decay- over a wide range of scales. Moreover, there is a general 69 agreement that the fractal behaviour of soil moisture is not simple 70 over extended scale ranges, and changes in time (Kim \& Barros, 71 2002b; Dubayah et al., 1997; Western et al., 2002). In particular, the 72 recent study of Das and Mohanty (2008) suggests a transition from 73 simple fractal (in wet fields) to multi-fractal (in dry fields) behaviour 74 during a dry-down period. In practice, the multi-fractal framework 75 seems an appropriate basis for downscaling soil moisture fields in 76 areas where ancillary data (e.g. topography, soil properties, vegeta- 77 tion, rainfall) are available at high resolution (Kim \& Barros, 2002a). 78

One drawback with statistical approaches is that they require a 79 large amount of data given that their validity domain is generally 80 limited to the conditions used for calibration. Consequently, there is a 81 need to develop methods that use physical and observable para- 82 meters. Bindlish and Barros (2002) developed an interpolation 83 method to downscale L-band passive microwave data using active 84 microwave data at the same wavelength to improve the resolution of 85 
brightness temperature fields prior to soil moisture retrieval. Similarly, Merlin et al. (2008a) developed a deterministic downscaling algorithm that combines $1 \mathrm{~km}$ resolution MODIS (MODerate resolution Imaging Spectroradiometer) data and a semi-empirical soil evaporative efficiency model. The main advantage of those approaches (Bindlish \& Barros, 2002; Merlin et al., 2008a) over the purely empirical ones based on log-log plots (e.g. Kim \& Barros, 2002a) is that some physical considerations are used to build a relationship between soil moisture and an ancillary observable; radar backscatter in Bindlish and Barros (2002) and soil evaporative efficiency in Merlin et al. (2008a).

In Merlin et al. (2008a), the disaggregation scale was fixed to 10 times the spatial resolution of MODIS thermal data to reduce the random uncertainties in disaggregated soil moisture. The authors observed that the sub-pixel variability of disaggregated soil moisture was significantly correlated with the observed fine-scale soil moisture variability, suggesting that the downscaling algorithm could be applied to spatial resolutions finer than $10 \mathrm{~km}$. Nevertheless, that study did not apply the downscaling approach at multiple resolutions.

As a follow-up of Merlin et al. (2008a), this paper seeks to identify optimal downscaling resolutions in terms of disaggregation accuracy and sub-pixel spatial variability, and demonstrate the utility of this approach for sequential disaggregation of spaceborne surface soil moisture observations using multi-resolution thermal sensors. The development of a sequential approach is motivated by (i) the fact that high-resolution thermal data such as ASTER (Advanced Scanning Thermal Emission and Reflection Radiometer) data generally have a swath width smaller than the SMOS pixel and (ii) the hypothesis that the use of an intermediate resolution provides a better linearized approximation to a non linear function (e.g. soil evaporative efficiency model). One objective of the paper is to assess this hypothesis using data collected during the three-week National Airborne Field Experiment 2006 (NAFE'06). Airborne L-band data are used to simulate the $40 \mathrm{~km}$ resolution pixels expected from SMOS, and a thermal-based disaggregation algorithm is applied using MODIS and ASTER data. While the first part of the paper focuses on estimating optimal downscaling resolutions with MODIS and ASTER data, the second part takes advantage of these results to develop a sequential model for disaggregating $\sim 40 \mathrm{~km}$ resolution microwave-derived soil moisture to $500 \mathrm{~m}$.

\section{Data}

The NAFE'06 was conducted from 31 October to 20 November 2006 over a $40 \mathrm{~km}$ by $60 \mathrm{~km}$ area near Yanco $\left(-35^{\circ} \mathrm{N} ; 146^{\circ} \mathrm{E}\right)$ in southeastern Australia. While a full description of the data set is given in Merlin et al. (2008b), a brief overview of the most pertinent details are provided here. The data used in this study are comprised of wind speed measurements, L-band derived soil moisture and MODIS data collected over the Yanco area on twelve days, and ground measurements of $0-5 \mathrm{~cm}$ soil moisture and ASTER data collected over three $9 \mathrm{~km}^{2}$ areas included in the Yanco area on one day (16 November) of the experiment.

\subsection{Wind speed}

Wind speed was monitored at $2 \mathrm{~m}$ by a meteorological station (located in the southwestern corner of the Yanco area, see Fig. 1 of Merlin et al. (2008b)) continuously during NAFE'06 with a time step of $20 \mathrm{~min}$. The time series is illustrated in Fig. 1 of Merlin et al. (2008a).

\subsection{Ground soil moisture}

In situ measurements of $0-5 \mathrm{~cm}$ soil moisture were made using HDAS (Hydraprobe Data Acquisition System) on 16 November over three $9 \mathrm{~km}^{2}$ sampling areas (denoted as Y2, Y9 and Y12) included in 146 the $40 \mathrm{~km}$ by $60 \mathrm{~km}$ Yanco area (Merlin et al., 2008b). Within each 147 $9 \mathrm{~km}^{2}$ sampling area, an average of three successive measurements 148 was made $\sim 1 \mathrm{~m}$ apart at each node of a $250 \mathrm{~m}$ resolution grid.

\subsection{PLMR-derived soil moisture}

The near-surface soil moisture was retrieved from the $1 \mathrm{~km} 151$ resolution brightness temperature collected by the Polarimetric L-band 152 Multibeam Radiometer (PLMR) on eleven days over the $40 \mathrm{~km}$ by $60 \mathrm{~km} 153$ area: 31 October, 2, 3, 4, 5, 7, 9, 13, 14, 16, 18 November (Merlin et al., 154 2009). The surface temperature data used for the PLMR soil moisture 155 inversion came from MODIS data on clear sky days, and from in situ 156 measurements on overcast days. The root mean square difference 157 between PLMR-derived and ground-measured soil moisture at $1 \mathrm{~km} 158$ resolution was estimated to $0.03 \mathrm{vol}$./ vol. in non-irrigated areas. A bias of 159 about -0.09 vol./vol. was obtained over pixels including some irrigation. 160 This bias was explained by a difference in sensing depth between the 161 L-band radiometer $(\sim 0-3 \mathrm{~cm})$ and in situ measurements $(0-5.7 \mathrm{~cm}), 162$ associated with a strong vertical gradient in the top $0-6 \mathrm{~cm}$ of the 163 soil. Moreover on 3 November, which followed a rainfall event, the 164 PLMR-derived soil moisture seemed to be affected by the presence of 165 water intercepted by vegetation (Merlin et al., 2008b,a). In this study, 166 data from this date were discarded.

\subsection{MODIS data}

168

The MODIS data used in this paper are the Version 5 MODIS/Terra 169 (10:30 am) and MODIS/Aqua (1:30 pm) $1 \mathrm{~km}$ resolution daily surface 170 temperature, and MODIS/Terra $250 \mathrm{~m}$ resolution 16-day Normalized 171 Difference Vegetation Index (NDVI). The 16-day NDVI product was cloud 172 free. In between the first (31 October) and last day (18 November) of 173 $1 \mathrm{~km}$ resolution PLMR flights over the Yanco area, sixteen MODIS 174 Version 5 surface temperature images with $0 \%$ cloud cover were 175 acquired including nine aboard Terra $(3,5,7,8,9,10,11,17,18$ November $) 176$ and seven aboard Aqua (31 October, 3, 4, 6, 8, 9, 17 November). Note that 177 more cloud free images were obtained than from Version 4 surface 178 temperature (Merlin et al., 2008a). The overestimation of cloud cover in 179 Version 4 products and the subsequent increase of coverage in Version 5180 land surface temperature products are discussed in Wan (2008). MODIS 181 data were re-sampled on the same $1 \mathrm{~km}$ resolution grid as PLMR- 182 derived soil moisture, and MODIS surface temperature was shifted of 183 $(+1 \mathrm{~km} \mathrm{E} ;-0.5 \mathrm{~km} \mathrm{~N})$ and $(+2 \mathrm{~km} \mathrm{E} ; 0 \mathrm{~N})$ for Terra and Aqua 184 respectively to maximize the spatial correlation with $1 \mathrm{~km}$ resolution 185 MODIS NDVI, which was used as a reference for the co-registration. 186

\subsection{ASTER data}

187

The ASTER/Terra overpass of the NAFE'06 site was on 16 November 188 2006 at 10:30 am. Radiometric surface temperature was estimated 189 from $90 \mathrm{~m}$ resolution $\mathrm{L} 1 \mathrm{~B}$ thermal radiances using the emissivity 190 normalization method developed by Gillespie (1985) and Realmuto 191 (1990) and implemented in ENVI (ENvironment for Visualizing 192 Images, http://www.ittvis.com/envi/) image processing software. 193 Temperature was computed for each of the five thermal channels 194 using a uniform emissivity set to 1, and the actual radiometric 195 temperature was assumed to be equal to the highest computed 196 temperature. Pre-processing of ASTER-derived radiometric tempera- 197 ture consisted of (i) registering the image with an accuracy better than 198 $90 \mathrm{~m}$ from reference points (ii) extracting data over three $12 \mathrm{~km}$ by 199 $12 \mathrm{~km}$ areas centered over the three $9 \mathrm{~km}^{2}$ sampling areas, (iii) 200 removing data that were visually identified as cloud or as cloud shade 201 on the ground (note that the scene was cloud free over the three 202 $9 \mathrm{~km}^{2}$ sampling areas Y2, Y9 and Y12)and (iv) re-sampling data at 203 $100 \mathrm{~m}$ resolution. An important point is that ASTER-derived radio- 204 metric surface temperature was not corrected for atmospheric effects. 205 
The rationale is that only the spatial variability of surface temperature (about the mean) is used by the thermal-based disaggregation algorithm of Merlin et al. (2008a). In other words, there is no need for absolute values of surface temperature. Moreover, atmospheric corrections are generally made at a scale of several tens of kilometers (Thome et al., 1998), which is larger than the application scale $(12 \mathrm{~km}$ in this study). Similar pre-processing was done on $15 \mathrm{~m}$ resolution ASTER red and near-infrared reflectances to derive $100 \mathrm{~m}$ resolution NDVI over the three $12 \mathrm{~km}$ by $12 \mathrm{~km}$ areas.

\section{Towards an optimal downscaling resolution}

The trade-off between downscaling resolution and accuracy within a disaggregation framework was already mentioned in a previous study (Merlin et al., 2008a). However, Merlin et al. (2008a) did not apply the downscaling approach at multiple resolutions. One objective of this paper is to identify the optimal downscaling resolution(s) in terms of disaggregation accuracy when using data from three sensors: MODIS aboard Terra, MODIS aboard Aqua and ASTER.

\subsection{Approach}

The approach adopted is to (i) aggregate reference (either PLMRderived or HDAS-measured) soil moisture to the maximum spatial extent ( $40 \mathrm{~km}$ by $60 \mathrm{~km}$ for PLMR and $3 \mathrm{~km}$ by $3 \mathrm{~km}$ for HDAS), (ii) apply the disaggregation method at a range of resolutions, and (iii) compare the disaggregated soil moisture to the reference data for each downscaling resolution. The disaggregation of soil moisture thus requires simultaneous observations of surface temperature and NDVI. Moreover, validation requires soil moisture observations at a common spatial resolution. Among the twelve dates with at least one (either Terra or Aqua) MODIS image with 0\% cloud cover, seven are concurrent with PLMR $1 \mathrm{~km}$ resolution flights. For the other five dates $(6,8,10,11$ and 17 November), the PLMR-derived soil moisture data of the day before are used. This extrapolation is valid because no rainfall occurred between the PLMR flight and MODIS overpass on each date. Data are listed in Table 1.

Data derived from MODIS, PLMR, ASTER and HDAS are then aggregated to a range of spatial resolutions. MODIS surface temperature, MODIS NDVI and PLMR soil moisture are aggregated successively from 1 to $12 \mathrm{~km}$ in $1 \mathrm{~km}$ increments over the $40 \mathrm{~km}$ by $60 \mathrm{~km}$ area. Similarly, ASTER surface temperature, ASTER NDVI and HDAS soil moisture are aggregated successively from 100 to $1200 \mathrm{~m}$ in $100 \mathrm{~m}$ increments over the three $9 \mathrm{~km}^{2}$ sampling areas. One should note that the spacing between ground measurements $(250 \mathrm{~m})$ was smaller than the two first aggregation resolutions ( 100 and $200 \mathrm{~m}$ ). For these two resolutions, the pixels including no ground measurement were

List of acquisition dates, mean PLMR-derived soil moisture, wind speed measured at Terra (T) or Aqua (A) overpass time (10:30 am/1:30 pm), and minimum MODIS/Terra, MODIS/Aqua and ASTER surface temperature.

\begin{tabular}{|c|c|c|c|c|c|c|}
\hline \multirow[t]{2}{*}{ Date } & \multirow{2}{*}{$\frac{\text { SM }_{\text {PLMR,40 }}}{\text { vol./vol. }}$} & \multicolumn{2}{|c|}{$u\left(\mathrm{~m} \mathrm{~s}^{-1}\right)$} & \multicolumn{2}{|l|}{$T_{\min , 1}\left({ }^{\circ} \mathrm{C}\right)$} & \multirow[t]{2}{*}{ ASTER } \\
\hline & & $\overline{\mathrm{T}}$ & A & MODIS/T & MODIS/A & \\
\hline 31 October & 0.046 & & 6.0 & & 36.2 & \\
\hline 4 November & 0.11 & & 7.6 & & 36.5 & \\
\hline 5 November & 0.065 & 5.0 & & 35.0 & & \\
\hline 6 November & $0.065^{*}$ & & 7.5 & & 37.6 & \\
\hline 7 November & 0.043 & 7.4 & & 33.3 & & \\
\hline 8 November & $0.043 *$ & 9.4 & 6.3 & 31.7 & 35.4 & \\
\hline 9 November & 0.040 & 10.5 & 4.1 & 31.4 & 37.7 & \\
\hline 10 November & $0.040 *$ & 11.9 & & 36.1 & & \\
\hline 11 November & $0.040 *$ & 5.3 & & 36.8 & & \\
\hline 16 November & 0.11 & 13.0 & & & & 19.0 \\
\hline 17 November & $0.11^{*}$ & 4.5 & 3.6 & 32.2 & 36.3 & \\
\hline 18 November & 0.055 & 5.1 & & 34.7 & & \\
\hline
\end{tabular}

* PLMR data from the day before. discarded from the analysis and only pixels immediately over the 248 ground measurement sites included. For simplicity, the different 249 spatial resolutions will be denoted using the subscript $n$, varying from 250 1 (native resolution) to 12 (for instance, $\mathrm{SM}_{\mathrm{PLMR}, 4}$ refers to PLMR- 251 derived soil moisture aggregated at $4 \mathrm{~km}$ resolution and $\mathrm{SM}_{\mathrm{mHDAS}, 5} 252$ refers to HDAS-measured soil moisture aggregated at $500 \mathrm{~m} 253$ resolution).

\subsection{Disaggregation method}

The thermal-based disaggregation approach used in this paper is 256 that developed in Merlin et al. (2008a). The equations below 257 represent the case of disaggregation using MODIS data for SMOS- 258 resolution pixels simulated by aggregating PLMR-derived soil moist- 259 ure. Note that all equations also apply for disaggregation using ASTER 260 data.

The soil moisture $\mathrm{SM}_{\mathrm{MODIS}, n}$ disaggregated at $n \mathrm{~km}$ resolution at first 262 order around the SMOS-resolution soil moisture SM $_{\text {PLMR } 40}$ is written as 263

$\mathrm{SM}_{\mathrm{MODIS}, n}=\mathrm{SM}_{\mathrm{PLMR}, 40}+\frac{\partial \mathrm{SM}}{\partial \mathrm{SEE}} \Delta \mathrm{SEE}_{\mathrm{MODIS}, n}$

with $\partial \mathrm{SM} / \partial \mathrm{SEE}$ being the partial derivative (evaluated at $\mathrm{SM}_{\mathrm{SMOS}, 40}$ ) $26 \mathrm{~g}$ of soil moisture to soil evaporative efficiency (SEE), and $\triangle \mathrm{SEE}_{n}$ the 266 difference between the MODIS-derived SEE estimated at $n \mathrm{~km} 267$ resolution and its average within the SMOS pixel. Eq. (1) can be 268 further simplified by using the simple expression of SEE from Komatsu 269 (2003). The downscaling relationship becomes

$\mathrm{SM}_{\mathrm{MODIS}, n}=\mathrm{SM}_{\mathrm{PLMR}, 40}+\mathrm{SM}_{\mathrm{C}} \times \mathrm{SMP}_{\mathrm{MODIS}, n}$

with $\mathrm{SM}_{\mathrm{C}}$ being a semi-empirical parameter that depends on soil type 272 and boundary layer conditions and SMP a normalized soil moisture 273 proxy. In Merlin et al. (2008a), the SMP was defined as

$\mathrm{SMP}_{\mathrm{MODIS}, n}=\frac{T_{\mathrm{MODIS}, 40}-T_{\mathrm{MODIS}, n}}{T_{\mathrm{MODIS}, 40}-T_{\min , 1}}$

with $T_{\mathrm{MODIS}, n}$ being the soil temperature estimated using MODIS- 276 derived NDVI and surface temperature, $T_{\text {MODIs,40 }}$ its average within the 277 SMOS pixel, and $T_{\min , 1}$ the minimum MODIS-derived soil temperature at 278 $1 \mathrm{~km}$ resolution. Note that the minimum soil temperature was 279 approximated to the minimum MODIS surface temperature. In Komatsu 280 (2003), the parameter $\mathrm{SM}_{\mathrm{C}}$ was calibrated for three different soils as 281 function of wind speed

$\mathrm{SM}_{\mathrm{C}}=\mathrm{SM}_{\mathrm{C} 0}\left(1+\frac{\gamma}{r_{a h}}\right)$

with $\mathrm{SM}_{\mathrm{CO}}$ (vol./vol.) being a soil-dependent parameter (ranging from $28 \mathrm{Z}$ about $0.01 \mathrm{vol}$./vol. for sand to $0.04 \mathrm{vol}$./vol. for clay), and $r_{a h}\left(\mathrm{~s} \mathrm{~m}^{-1}\right) 285$ the aerodynamic resistance over bare soil. Aerodynamic resistance can 286 be estimated from wind speed measurements $u\left(\mathrm{~m} \mathrm{~s}^{-1}\right)$ at reference 287 height $Z(\mathrm{~m})$ given the soil roughness $\mathrm{z}_{0 \mathrm{~m}}(\mathrm{~m})$

$r_{a h}=\frac{1}{k^{2} u}\left[\ln \left(\frac{Z}{z_{0 m}}\right)\right]^{2}$

with $k$ being the von Karman constant. The soil temperature in Eq. (3) is 289 estimated as

$T_{\mathrm{MODIS}, n}=\frac{T_{\mathrm{surf}, \mathrm{MODIS}, n}-f_{\mathrm{v}, \mathrm{MODIS}, n} T_{\mathrm{v}, n}}{1-f_{\mathrm{V}, \mathrm{MODIS}, n}}$

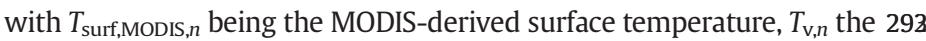
vegetation temperature, and $f_{\mathrm{v}, \mathrm{MODIS}, n}$ the fractional vegetation cover. In 294 Merlin et al. (2008a), the vegetation temperature was approximated to 295 
$f_{\mathrm{V}, \mathrm{MODIS}, n}=\frac{\mathrm{NDVI}_{\mathrm{MODIS}, n}-\mathrm{NDVI}_{\min }}{\mathrm{NDVI}_{\max }-\mathrm{NDVI}_{\min }}$

$T_{\min , 1}$ by assuming that vegetation was not undergoing water stress, and fractional vegetation cover was estimated as

with $\mathrm{NDVI}_{\min }$ and $\mathrm{NDVI}_{\max }$ being the NDVI value that corresponds to bare soil and fully vegetated pixels respectively.

In this study, parameters $\mathrm{SM}_{\mathrm{CO}}, \mathrm{NDVI}_{\min }$ and $\mathrm{NDVI}_{\max }$, as well as wind speed $\left(r_{a h}\right)$ are assumed to be uniform within the SMOS pixel (model parameters are listed in Table 2). This invariance assumption will be further assessed in view of the disaggregation results obtained at a range of spatial resolutions.

\subsection{Downscaling resolution versus disaggregation accuracy}

Two different criteria are developed to estimate an optimal downscaling resolution for each of the three sensors. The first criterion denoted $\mathrm{C} 1$ is the condition that the disaggregation error evaluated at the downscaling resolution is equal to the observed subpixel variability. Intuitively, if the error on disaggregated soil moisture is smaller than the sub-pixel variability, then the downscaling resolution is too coarse to represent the actual variability; and conversely if the error is larger, then the downscaling resolution is too fine. $\mathrm{C} 1$ can be formulated as

$\mathrm{RMSE}_{n, n}=\overline{\mathrm{SD}_{n, 1}}$

with $\mathrm{RMSE}_{n, n}$ being the root mean square error evaluated at the $(n \mathrm{~km})$ disaggregation resolution between disaggregated and PLMRderived soil moisture, and $\overline{\mathrm{SD}_{n, 1}}$ the mean standard deviation of $1 \mathrm{~km}$ resolution PLMR-derived soil moisture computed within each $n^{2} \mathrm{~km}^{2}$ pixel. The $n \mathrm{~km}$ resolution error is computed as

$\operatorname{RMSE}_{n, n}=\left[\frac{1}{N / n^{2}} \sum\left(\mathrm{SM}_{\mathrm{MODIS}, n}-\mathrm{SM}_{\mathrm{PLMR}, n}\right)^{2}\right]^{0.5}$

with $N$ being the number of $1 \mathrm{~km}$ resolution pixels within the $40 \mathrm{~km}$ by $60 \mathrm{~km}$ study area. The mean sub-pixel variability is computed as

$\overline{\mathrm{SD}_{n, 1}}=\frac{1}{N / n^{2}} \sum \mathrm{SD}_{n, 1}$

$$
=\frac{1}{N / n^{2}} \sum\left[\frac{1}{n^{2}-1} \sum\left(\mathrm{SM}_{\mathrm{PLMR}, n}-\mathrm{SM}_{\mathrm{PLMR}, 1}\right)^{2}\right]^{0.5}
$$

The second criterion denoted $\mathrm{C} 2$ is the condition that the error evaluated at the native resolution $(n=1)$ is minimum. In other words, C2 is satisfied when the downscaling resolution makes the disaggregation output the most accurate with respect to the reference soil moisture data obtained at the thermal sensor native resolution. $\mathrm{C} 2$ can be formulated as

$\mathrm{RMSE}_{n, 1}=\left[\frac{1}{N} \sum\left(\mathrm{SM}_{\mathrm{MODIS}, n}-\mathrm{SM}_{\mathrm{PLMR}, 1}\right)^{2}\right]^{0.5}$ is minimum

with $\mathrm{RMSE}_{n, 1}$ being the root mean square error evaluated at $1 \mathrm{~km}$ resolution between the $n \mathrm{~km}$ resolution disaggregated and $1 \mathrm{~km}$ resolution PLMR-derived soil moisture.

The criteria C1 and C2 can be applied to the three farms Y2, Y9 and Y12 by replacing in Eqs. (8) to (12), PLMR and MODIS by HDAS and ASTER respectively.
Table 2

Model parameters.

\begin{tabular}{llll}
\hline Parameter & Value & Unit & Source \\
\hline $\mathrm{SM}_{\mathrm{C0}}$ & 0.04 & vol./vol. & Komatsu (2003) \\
$\gamma$ & 100 & $\mathrm{~s} \mathrm{~m}^{-1}$ & Komatsu (2003) \\
$\mathrm{z}_{0 m}$ & 0.005 & $\mathrm{~m}$ & Liu et al. (2007) \\
NDVI $_{\min }$ & 0 & - & Agam et al. (2007) \\
NDVI $_{\max }$ & 1 & - & Agam et al. (2007) \\
\hline
\end{tabular}

\subsection{Application to MODIS}

The disaggregation algorithm of Eq. (2) is applied to each of the 343 eight MODIS/Terra images (5, 7, 8, 9, 10, 11, 17 and 18 November) and 344 to each of the six MODIS/Aqua images (31 October, 4, 6, 8, 9 and 17345 November), with a downscaling resolution ranging from 1 to $12 \mathrm{~km}$. 346 Fig. 1 plots the $n \mathrm{~km}$ resolution disaggregated soil moisture versus the 347 $n \mathrm{~km}$ resolution PLMR-derived soil moisture for $n=1,2,4,8$ and 12. It 348 is apparent that the noise on disaggregated soil moisture is 349 successively reduced by increasing the downscaling resolution. 350 However, the range of soil moisture values is also reduced and 351 consequently the larger the resolution, the more limited the spatial 352 representation of the actual soil moisture heterogeneity is. 353

As MODIS data were used for the PLMR soil moisture inversion, 354 PLMR-derived and MODIS-disaggregated soil moisture are theoreti- 355 cally not fully independent on clear sky days. However, it is argued 356 that the cross-correlation of errors in the PLMR soil moisture 357 measurements and the disaggregated soil moisture fields is not 358 responsible for the good results in Fig. 1. One simple reason is that 359 MODIS temperature has a positive impact on PLMR soil moisture 360 retrievals (increasing with MODIS temperature) and a negative 361 impact on disaggregated soil moisture (decreasing with MODIS 362 temperature). Consequently, the cross-correlation of errors in PLMR- 363 derived and MODIS-disaggregated soil moisture would actually make 364 the results poorer.

Fig. 2 plots the $\operatorname{RMSE}_{n, n}$ evaluated at the downscaling resolution as 366 a function of $n$ for each MODIS overpass date, separated according to 367 Aqua and Terra data. The average for all dates is also plotted for each 368 platform. The mean error decreases from about $0.045 \mathrm{vol}$./ vol. at $1 \mathrm{~km} 369$ resolution to about $0.015 \mathrm{vol}$./ vol. at $12 \mathrm{~km}$ resolution for both Aqua 370 and Terra. On the same graph is plotted the mean sub-pixel variability 371 $\overline{\mathrm{SD}_{n, 1}}$ for all dates. The mean sub-pixel variability increases from 0 to 372 about $0.04 \mathrm{vol} . / \mathrm{vol}$. at 1 and $12 \mathrm{~km}$ resolution respectively for both 373 Aqua and Terra. The standard deviation is equal to 0 at $1 \mathrm{~km}$ resolution 374 because only one PLMR measurement is available per downscaled 375 pixel at $1 \mathrm{~km}$ resolution. Following criterion C1 in Eq. (8), an optimal 376 downscaling resolution exists where the RMSE and spatial variability 377 lines cross. Inspection of Fig. 2 shows that the mean optimal resolution 378 is about $3.7 \mathrm{~km}$ for MODIS aboard Aqua and $4.2 \mathrm{~km}$ for MODIS aboard 379 Terra. Although relatively similar for both sensors, the RMSE of 380 disaggregated soil moisture are remarkably more spread about the 381 mean for Terra than for Aqua. The more consistent disaggregation 382 results using MODIS/Aqua compared to MODIS/Terra was already 383 mentioned in (Merlin et al., 2008a) when applied to $10 \mathrm{~km}$ resolution. 384 This is due to the stronger coupling between SEE and soil moisture at 385 $1: 30 \mathrm{pm}$ than at 10:30 am.

386

Fig. 3 plots the average and standard deviation of the error RMSE $_{n, 1} 387$ (evaluated at the thermal sensor native resolution) as a function $n$ for 388 Aqua and Terra data. The mean error is higher for Terra than for Aqua, 389 which is consistent with previous results. For both Terra and Aqua, the 390 mean error slightly decreases as spatial resolution increases from 1 to 391 $5 \mathrm{~km}$, and slightly increases for spatial resolutions greater than $5 \mathrm{~km} .392$ Following criterion C2, an optimal downscaling resolution is identified 393 at about $5 \mathrm{~km}$ for both MODIS/Terra and MODIS/Aqua. Nevertheless, 394 the minimum of $\operatorname{RMSE}_{n, 1}$ is not very well defined since the dynamics 395 of the mean value are smaller than the variability observed within the 396 

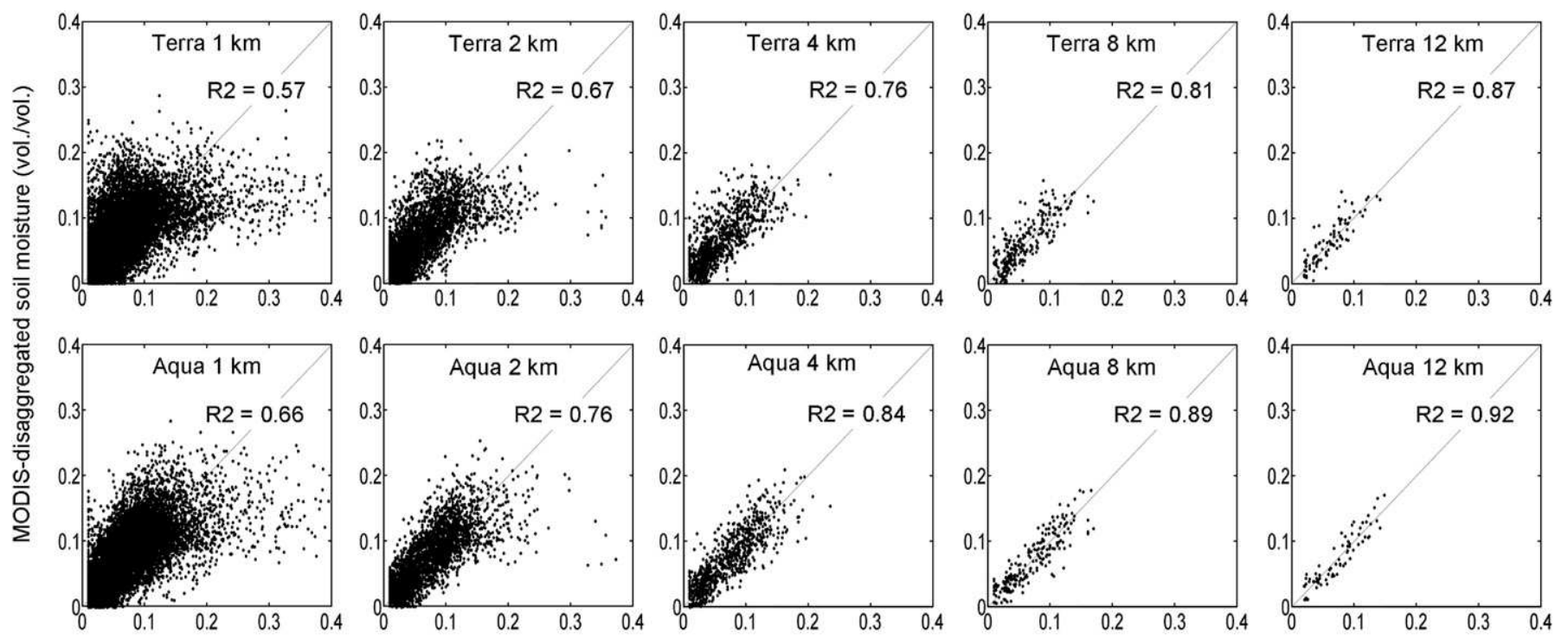

PLMR-derived soil moisture (vol./vol.)

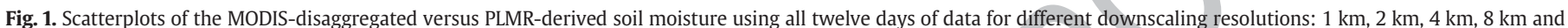
$12 \mathrm{~km}$. The correlation coefficient R2 is indicated on each plot.

data set (shown on Fig. 3 by the standard deviation $\sigma$ ). One limitation of the criterion $\mathrm{C} 2$ is that it includes both the uncertainty in the disaggregation output and the uncertainty in PLMR-derived soil moisture at the observation scale, so that the $\operatorname{RMSE}_{n, 1}$ can never be lower than the measurement error at the native resolution.
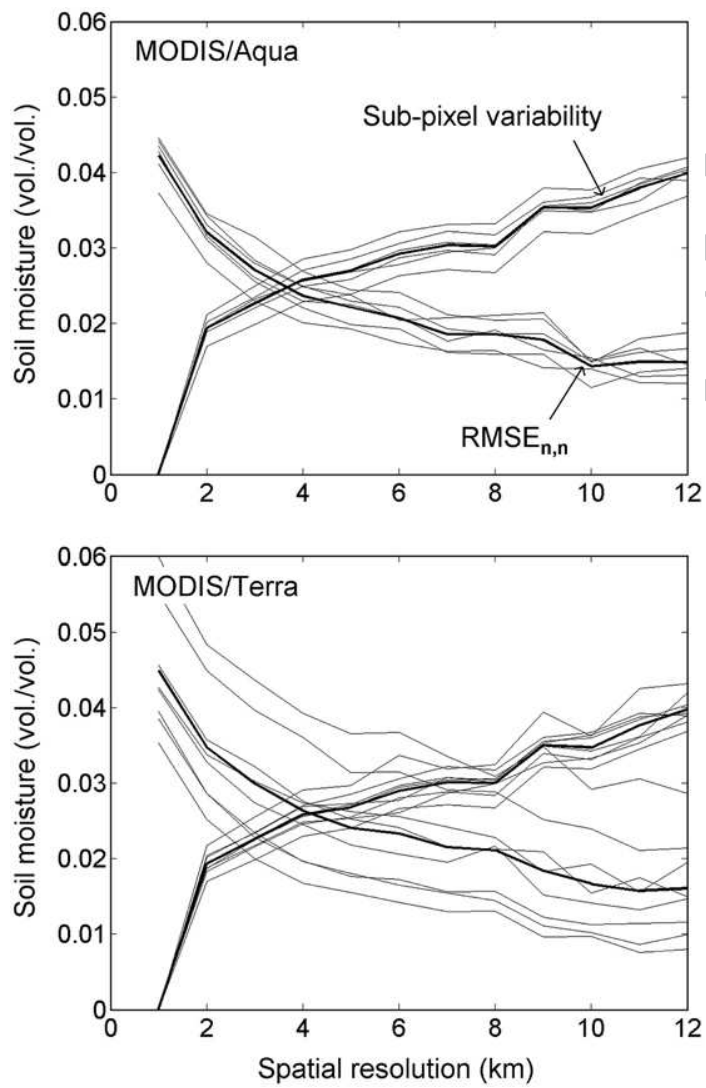

Fig. 2. Estimating an optimal downscaling resolution by comparing the root mean square error (RMSE) and the sub-pixel soil moisture variability at the disaggregation scale. The mean (thick line) RMSE is equal to the mean sub-pixel variability at about $4 \mathrm{~km}$ for both MODIS/Aqua and MODIS/Terra. The other lines represent the different dates.
In summary, the application of criteria C1 and C2 to MODIS/PLMR 402 data demonstrates that the optimal downscaling resolution in terms 403 of disaggregation accuracy (using the NAFE'06 data set) is about 4 to 404 $5 \mathrm{~km}$. Also, criterion C1 is better defined than C2 since it smooths out 405 the uncertainties associated with random errors in PLMR-derived soil 406 moisture.
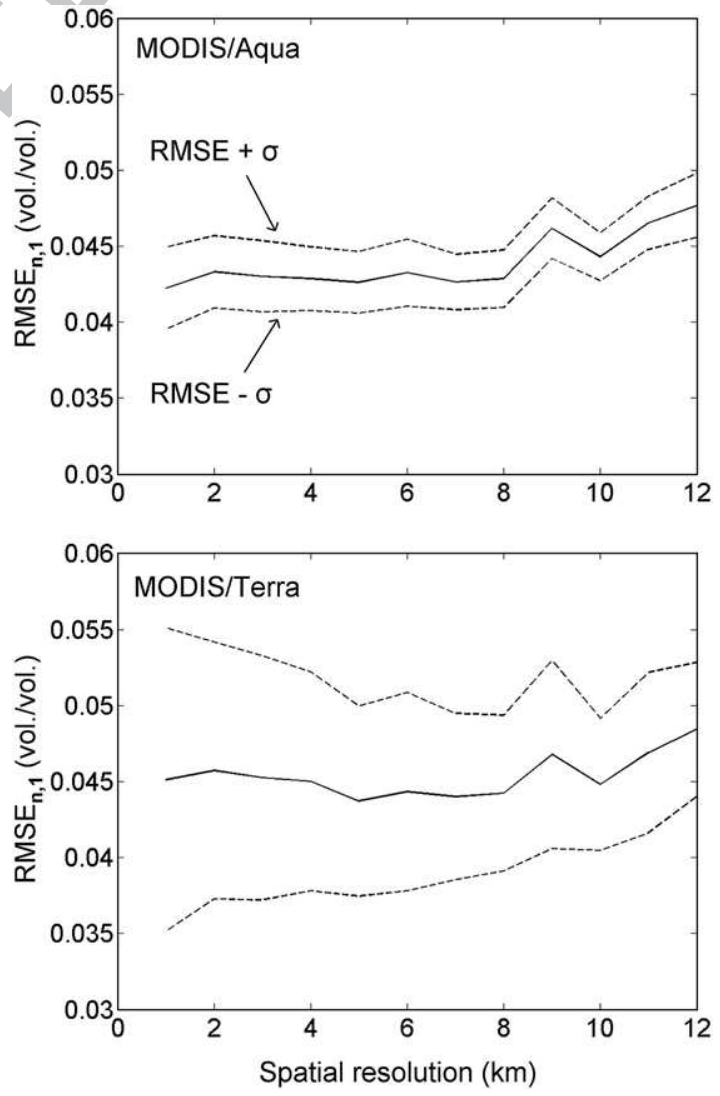

Fig. 3. Root mean square error (RMSE) evaluated at $1 \mathrm{~km}$ resolution for downscaling resolutions increasing from 1 to $12 \mathrm{~km}$. Although the standard deviation $(\sigma)$ between dates is high, the RMSE is minimum at $5 \mathrm{~km}$ for both MODIS aboard Aqua and MODIS aboard Terra. 


\subsection{Application to ASTER}

The same disaggregation approach is applied to the three $9 \mathrm{~km}^{2}$ sampling areas (Y2, Y9 and Y12) using the ASTER/HDAS data collected on 16 November, with a downscaling resolution ranging from 100 to $1200 \mathrm{~m}$. Fig. 4 plots the $n \times 100 \mathrm{~m}$ resolution disaggregated soil moisture versus the $n \times 100 \mathrm{~m}$ resolution aggregated HDAS measurements for $n=1,2,4,5,8$ and 12. As with MODIS/PLMR data, it is apparent that the accuracy on disaggregated soil moisture increases (and the range of downscaled values decreases) as the downscaling resolution increases. In Fig. 4, three data points are clearly aside from the $1: 1$ line for downscaling resolutions of $100 \mathrm{~m}$ and $200 \mathrm{~m}$. These correspond to the pixels that included a portion of rice field in Y9. Since rice crops were flooded during NAFE'06, no HDAS measurement was made. Consequently, the nearby ground measurements did not represent well the overall "wetness" (including both soil moisture and standing water) of the surface that the disaggregation algorithm actually represents.

When comparing Figs. 1 and 4, one observes that the disaggregation approach is much more accurate when applied to MODIS data than when applied to ASTER data. In particular for $n=8$, the correlation coefficient is about 0.80 for MODIS and0.60 for ASTER. The relatively poor results obtained using ASTER data can be interpreted as a consequence of the spatial variability of soil moisture at fine scale. As the typical crop size in the study area was about 100$300 \mathrm{~m}$, soil moisture fields were much more heterogeneous at $100 \mathrm{~m}$ resolution than at $1 \mathrm{~km}$ and above. It is suggested that point-scale measurements aggregated at $100-1000 \mathrm{~m}$ resolution were generally more uncertain than $1 \mathrm{~km}$ resolution remotely-sensed PLMR-derived soil moisture.

Fig. 5 plots the $\operatorname{RMSE}_{n, n}$ evaluated at the downscaling resolution as a function of $n$. It is apparent that the error is approximately constant at $100 \mathrm{~m}$ and $200 \mathrm{~m}$ resolution, which is consistent with the fact that the spacing $(250 \mathrm{~m})$ of HDAS measurements was larger than the thermal sensor native resolution so that the spatial variability of HDAS measurements is not represented below $300 \mathrm{~m}$. For all farms, the error is maximum at $200 \mathrm{~m}$, and is minimum at $1200 \mathrm{~m}$ resolution with a value of about $0.02 \mathrm{vol}$./vol. On the same graph is plotted the mean sub-pixel variability $\overline{\mathrm{SD}_{n, 1}}$ for each farm. The mean variability is about $0.02 \mathrm{vol} . / \mathrm{vol}$. at $n=1$ and is generally maximum at $n=12$. Note that
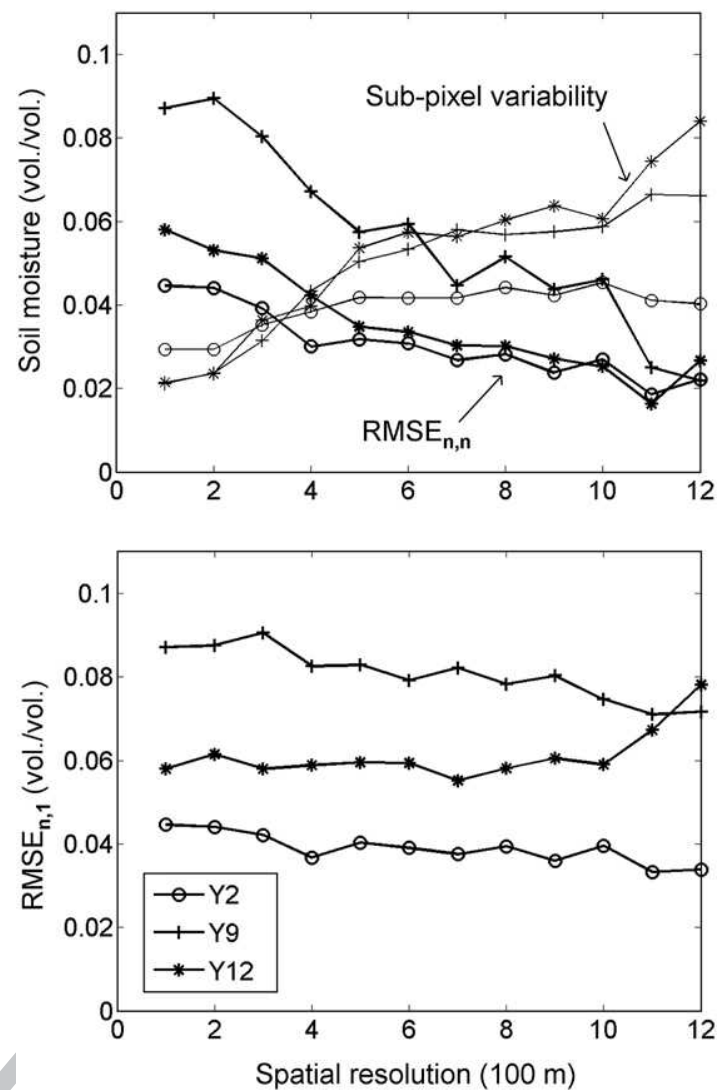

Fig. 5. Root mean square error (RMSE) evaluated at the downscaling resolution (top) and at $100 \mathrm{~m}$ resolution (bottom) for downscaling resolutions increasing from 100 to

$1200 \mathrm{~m}$.

its value at $n=1$ is not equal to zero as in the case of PLMR data, 447 because three successive measurements were made at each sampling 448 point, providing the mean local-scale variability of HDAS measure- 449 ments. Following criterion C1 in Eq. (8), the optimal downscaling 450 resolution for each farm is identified at $300 \mathrm{~m}, 400 \mathrm{~m}$ and $600 \mathrm{~m}$ for 451 Y2, Y9 and Y12 respectively.
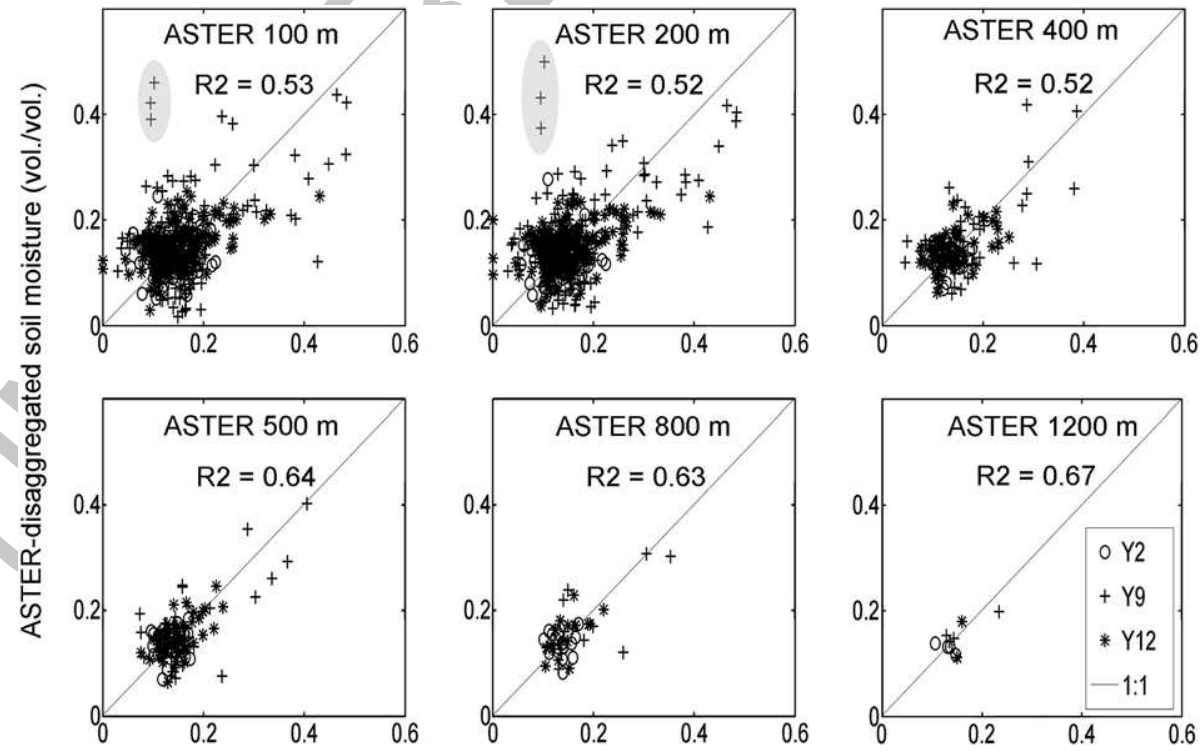

Ground-measured soil moisture (vol./vol.)

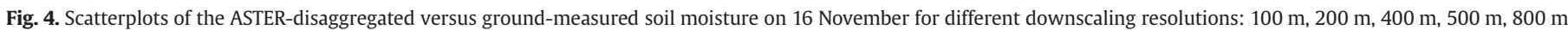
and $1200 \mathrm{~m}$. Highlighted pluses correspond to pixels containing standing water (flooded rice fields). The correlation coefficient R2 is indicated on each plot. 
Fig. 5 also plots the error $\operatorname{RMSE}_{n, 1}$ evaluated at the ASTER native resolution ( $100 \mathrm{~m})$ as a function of $n$. Although one observes a minimum of the error for Y12 at $n=7$, no minimum is observed for the other farms (Y2 and Y9). Several hypotheses can be postulated to explain these constrasting results. First, when using ground measurements instead of airborne L-band data, reference soil moisture data are representative of the point-scale and may not be representative of the scales integrated to several hundreds of meters, especially over highly heterogeneous irrigated areas like in Y9. Second, the farm-scale variability in Y2 was about the same as the local-scale variability (uncertainty in a single HDAS measurement). Consequently, the disaggregation over that farm was not expected to improve the accuracy of soil moisture at fine scale. Third, it was seen in the case of MODIS/PLMR that criterion C2 was not very stable from date to date, so no clear result can be expected from only one date with ASTER/HDAS.

In summary, the application of criteria C1 and C2 to ASTER/HDAS data suggests that the optimal downscaling resolution in terms of disaggregation accuracy (using the NAFE'06 data set) is about 4 to 5 times the thermal sensor resolution. Criterion $\mathrm{C} 1$ is again found to be better defined than $\mathrm{C} 2$.

\section{Sequential disaggregation}

The general approach of the sequential disaggregation using multiresolution thermal sensors is presented in Fig. 6 . The $\sim 40 \mathrm{~km}$ resolution SMOS-scale soil moisture generated from PLMR data on 16 November is disaggregated at an intermediate resolution (4 km in Fig. 6) using 477 MODIS data and the MODIS-disaggregated soil moisture is disaggre- 478 gated again at a finer resolution using ASTER data. Note that the MODIS 479 data on 16 November were not cloud free over the $40 \mathrm{~km}$ SMOS-scale 480 pixel so that the MODIS data on 17 November were used instead.

\subsection{A sequential model}

The sequential model is written as

$\mathrm{SM}_{S_{i+1}}=\mathrm{SM}_{S_{i}}+\frac{\partial \mathrm{SM}}{\partial \mathrm{SEE}} \Delta \mathrm{SEE}_{S_{i+1}}$

with $S_{i}$ being the sensor of index $i$. In our case, $S_{0}, S_{1}$ and $S_{2} 48$ s corresponds to SMOS, MODIS and ASTER respectively. By using this 486 notation, Eqs. (2) and (3) become

$\mathrm{SM}_{S_{i+1}}=\mathrm{SM}_{S_{i}}+\mathrm{SM}_{\mathrm{C}} \times \mathrm{SMP}_{S_{i}}$

with

$\operatorname{SMP}_{S_{i+1}}=\frac{T_{S_{i}}-T_{S_{i}+1}}{T_{S_{i}}-T_{\text {min }}}$

From the above equations, one is able to identify the parameters that 490 do not vary with scale. In particular, the minimum soil temperature 492

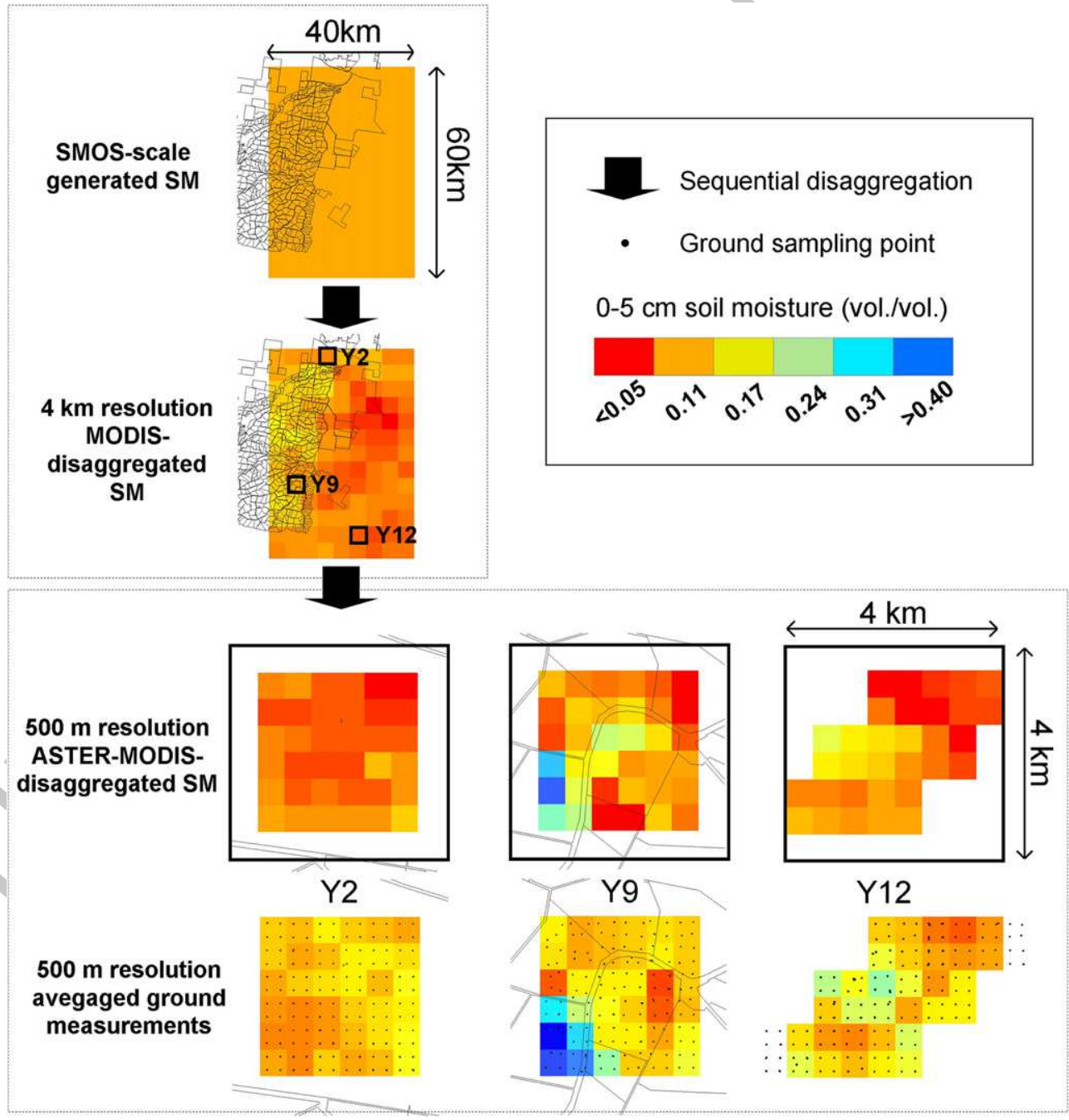

Fig. 6. Schematic diagram presenting the sequential disaggregation of SMOS-scale soil moisture using MODIS and ASTER data. 
$T_{\text {min }}$ and the soil property $\mathrm{SM}_{\mathrm{C}}$ are assumed to be scale-invariant. An important point is that these assumptions might not be valid in the case of heterogeneous soil within the SMOS-scale pixel. In particular, Merlin et al. (2008a) demonstrated that estimating $\mathrm{SM}_{\mathrm{C}}$ at high resolution improved significantly the disaggregation accuracy. However, the scale-invariance of $\mathrm{SM}_{C}$ was not tested in this paper since only one ASTER image was available whereas a time series would be required (Merlin et al., 2008a).

\subsection{Application}

Based on the results of the previous section, the intermediate resolution is set to four times the MODIS native resolution $(4 \mathrm{~km})$ and the target resolution to five times the ASTER native resolution $(500 \mathrm{~m})$. In practice, three data sets were derived by defining a $4 \mathrm{~km}$ resolution pixel centered on each of the three sampling areas (see black outlines in Fig. 6). This pixel was used to create over the SMOS-scale pixel a $4 \mathrm{~km}$ resolution grid, on which the $1 \mathrm{~km}$ resolution MODIS and PLMR data were aggregated. The sequential model of Eq. (14) was finally applied to each data set.

Fig. 7 plots the $4 \mathrm{~km}$ resolution MODIS-disaggregated soil moisture versus the $4 \mathrm{~km}$ resolution PLMR-derived soil moisture for each of the three data sets. The root mean square error is 0.026 vol./vol. Fig. 7 also plots the $500 \mathrm{~m}$ resolution ASTER-MODIS-disaggregated soil moisture versus the $500 \mathrm{~m}$ resolution HDAS-measured soil moisture in each farm. The sequentially disaggregated soil moisture has a RMSE of $0.062 \mathrm{vol} . / \mathrm{vol}$. and a bias of $-0.045_{\mathrm{N}} \mathrm{vol} . / \mathrm{vol}$. Results are degraded compared to the case when the ASTER-disaggregated soil moisture was based on HDAS-aggregated measurements and not on MODISdisaggregated soil moisture. The increase of uncertainty could be due
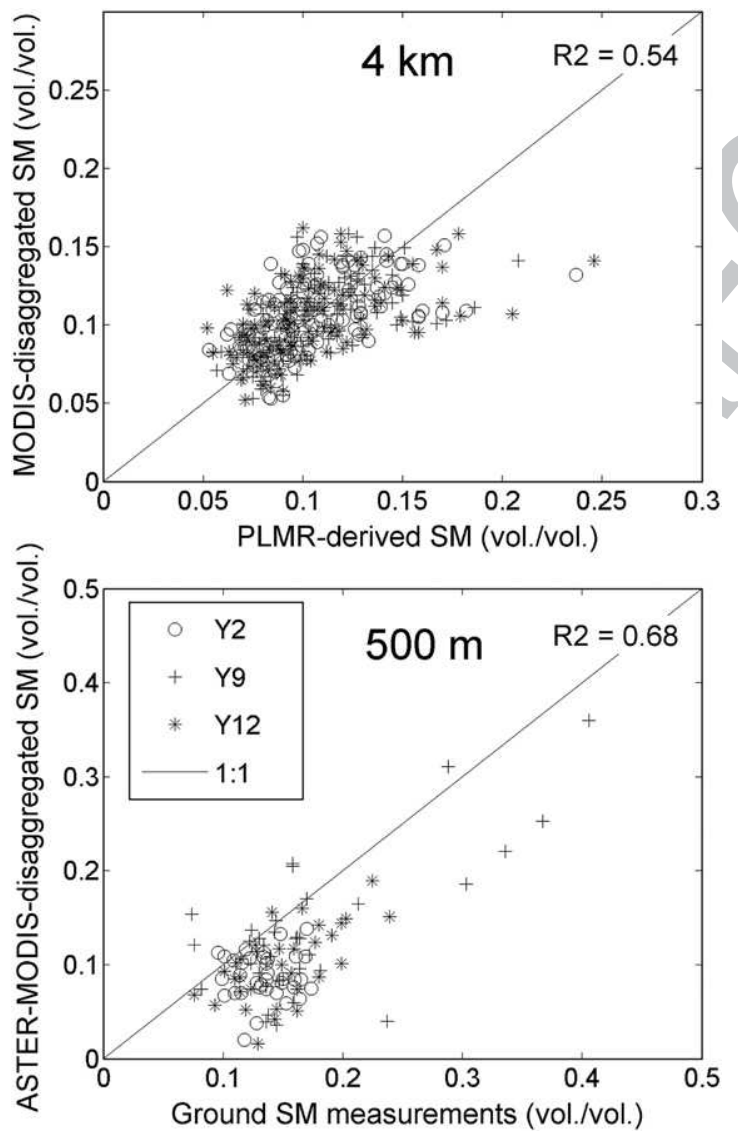

Fig. 7. Scatterplots of the $4 \mathrm{~km}$ resolution MODIS-disaggregated versus $4 \mathrm{~km}$ aggregated PLMR-derived soil moisture (top) and the $500 \mathrm{~m}$ resolution ASTER-MODIS-disaggregated versus 500 m HDAS measurements (bottom).

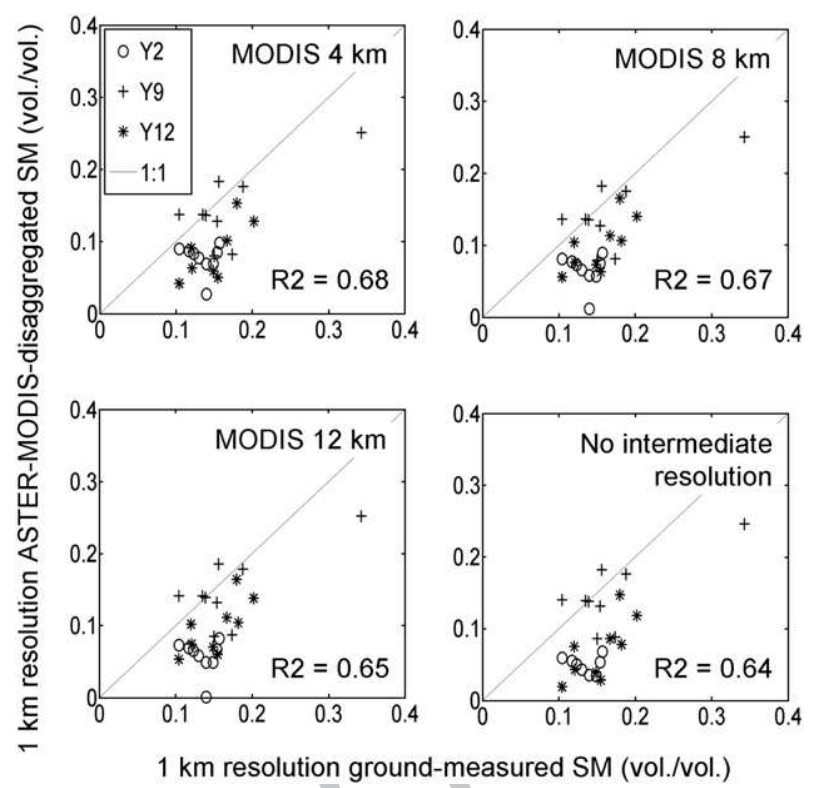

Fig. 8. Scatterplots of the $1 \mathrm{~km}$ resolution ASTER-MODIS-disaggregated soil moisture versus HDAS measurements for three different intermediate resolutions: $4 \mathrm{~km}, 8 \mathrm{~km}$ and $12 \mathrm{~km}$, and for the case of "no intermediate resolution".

to the disaggregation method and/or the soil moisture retrieval 521 algorithm. The bias on disaggregated soil moisture is estimated as 522 $-0.047,-0.040$ and -0.049 vol./ vol. for Y2, Y9 and Y12 respectively. 523 Although a persistent bias of about $-0.045 \mathrm{vol}$./vol. tends to 524 corroborate the hypothesis of a bias in the PLMR-derived soil moisture 525 on 16 November, no conclusion can be drawn from only three 526 independent data sets.

Errors on disaggregated soil moisture might also come from the 528 disaggregation method itself, which may not fully represent the non- 529 linear behaviour of the relationship between SEE and soil moisture. 530 The effect of this non-linearity is clearly visible in Fig 7 where MODIS- 531 disaggregated soil moisture tends to saturate at PLMR-derived soil 532 moisture values higher than $0.20 \mathrm{vol}$./vol. Moreover, our sequential 533 model did not account for the propagation of errors in the 534 disaggregation. In particular, a random error in MODIS-disaggregated 535 soil moisture at $4 \mathrm{~km}$ resolution would behave as a bias on $500 \mathrm{~m} 536$ resolution ASTER-MODIS-disaggregated soil moisture within each 537 $4 \mathrm{~km}$ resolution pixel.

One way to limit the increase of uncertainty associated with error 539 propagations would be to choose a coarser target resolution. In 540

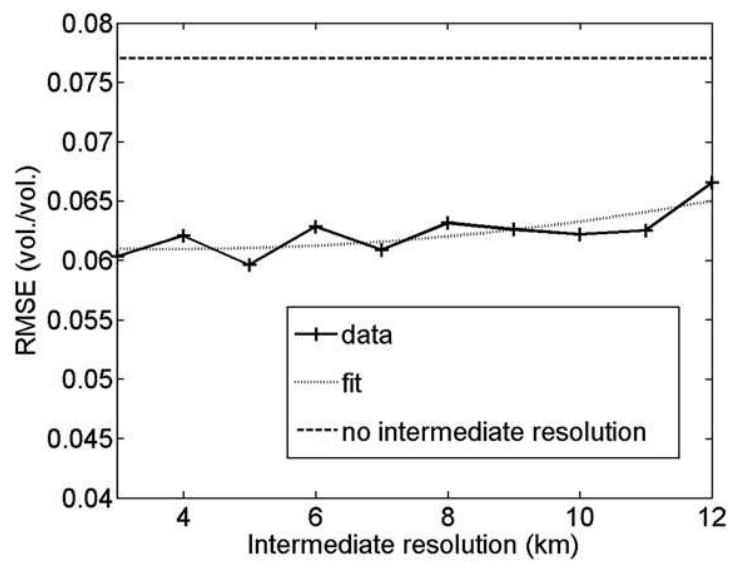

Fig. 9. Root mean square error on the $1 \mathrm{~km}$ resolution ASTER-MODIS-disaggregated soil moisture for an intermediate resolution increasing from 3 to $12 \mathrm{~km}$. The error obtained in the case of "no intermediate resolution" is also indicated. 
particular, output errors are expected to be reduced by setting the downscaling resolution to a value larger than the resolution that was found to be optimal when using one sensor (MODIS or ASTER) independently from the combination of both.

\subsection{Sensitivity to intermediate resolution}

Due to propagation errors from the coarser to finer resolutions, the combination of multi-source (MODIS and ASTER) data is likely to increase the disaggregation uncertainty. Consequently, one may argue that a more efficient approach than combining MODIS and ASTER data would be the direct disaggregation of SMOS-scale soil moisture using ASTER data only. The point is the swath width of ASTER $(60 \mathrm{~km})$ is much narrower than that of SMOS $(\sim 1000 \mathrm{~km})$. In particular, the $40 \mathrm{~km}$ by $60 \mathrm{~km}$ area covered by PLMR (SMOS-scale pixel) during NAFE'06 was not entirely covered by ASTER. Therefore, the disaggregation of SMOS-scale soil moisture requires thermal data at an intermediate resolution (MODIS) before the use of high-resolution (ASTER) data over smaller focus areas.

To assess the sensitivity of disaggregation results to intermediate resolution, an additional analysis is presented. The target resolution is now fixed to $1 \mathrm{~km}$, and the intermediate resolution is increased from 3 to $12 \mathrm{~km}$ in $1 \mathrm{~km}$ increments. The $1 \mathrm{~km}$ resolution ASTER-MODISdisaggregated soil moisture is then compared to ground measurements aggregated at $1 \mathrm{~km}$ resolution. Pre-processing included (i) defining a pixel with a resolution ranging from 3 to $12 \mathrm{~km}$ and covering each of the three $9 \mathrm{~km}^{2}$ sampling areas (ii) creating a 3-12 km resolution grid over the SMOS-scale pixel based on that pre-defined pixel and (iii) aggregating $1 \mathrm{~km}$ resolution MODIS and PLMR data at $3-12 \mathrm{~km}$ resolution on that pre-defined grid. The sequential model of Eq. (14) was finally applied to each data set for an intermediate resolution ranging from 3 to $12 \mathrm{~km}$.

Fig. 8 plots the $1 \mathrm{~km}$ resolution ASTER-MODIS-disaggregated versus HDAS-measured soil moisture for three different intermediate resolutions: 4,8 and $12 \mathrm{~km}$ and for the case of "no intermediate resolution". For the case "no intermediate resolution", the SMOS pixel is disaggregated at $1 \mathrm{~km}$ resolution directly using only the ASTER data. As the ASTER image did not entirely cover the SMOS pixel, the mean temperature required in Eq. (15) was estimated within the overlap area of ASTER and PLMR data, which represented about $80 \%$ of the SMOS pixel. The RMSE on sequentially disaggregated soil moisture is 0.060 and 0.077 vol./vol., the bias -0.049 and -0.063 vol. $/$ vol., and the correlation coefficient 0.68 and 0.64 at $4 \mathrm{~km}$ and $\tilde{\wedge} 40 \mathrm{~km}$ resolution respectively. The error is plotted as a function of intermediate resolution in Fig. 9. It is apparent that the error is minimum at $3-5 \mathrm{~km}$ and slightly increases with intermediate resolution, meaning that the optimal intermediate resolution is the highest. Note that the oscillation of the RMSE around its upward trend is mainly due to the change of the spatial extent of input data each time data are aggregated to a different intermediate resolution. For intermediate resolutions ranging from 3 to $12 \mathrm{~km}$, the error is lower than that obtained in the case of "no intermediate resolution". This shows that the use of MODIS data in the sequential disaggregation increases the accuracy on ASTER-disaggregated soil moisture. It is suggested that the use of an intermediate resolution between SMOS and ASTER is able to reduce the non-linearity effects across scales between soil evaporative efficiency and soil moisture, despite the increase of uncertainties associated with error propagations.

\section{Conclusion}

A sequential model was developed to disaggregate microwavederived soil moisture recursively from $40 \mathrm{~km}$ to $4 \mathrm{~km}$ resolution using MODIS data and from $4 \mathrm{~km}$ to $500 \mathrm{~m}$ resolution using ASTER data. The airborne and ground data collected during the three-week NAFE'06 were used to simulate coarse-scale pixels, and a thermal-based disaggregation algorithm was applied using $1 \mathrm{~km}$ resolution MODIS 603 and $100 \mathrm{~m}$ resolution ASTER data. A key step in the procedure was to 604 identify an optimal downscaling resolution in terms of disaggregation 605 accuracy and sub-pixel soil moisture variability by using two criteria. 606 The first criterion $\mathrm{C} 1$ was to look for the spatial resolution such that 607 the RMSE evaluated at the downscaling resolution be equal to the sub- 608 pixel soil moisture variability, while the second criterion C2 was to 609 look for the spatial resolution that minimized the RMSE evaluated at 610 the thermal sensor native resolution ( $1 \mathrm{~km}$ for MODIS or $100 \mathrm{~m}$ for 611 ASTER). Very consistent optimal downscaling resolutions were 612 obtained for MODIS aboard Terra, MODIS aboard Aqua and ASTER, 613 which were 4 to 5 times the thermal sensor resolution.

The $\sim 40 \mathrm{~km}$ resolution SMOS-scale soil moisture generated from 615 airborne L-band data on 16 November was disaggregated at an 616 intermediate resolution ( $4 \mathrm{~km}$ ) using MODIS data and the MODIS- 617 disaggregated soil moisture was disaggregated again at $500 \mathrm{~m} 618$ resolution using ASTER data. The RMSE between the $500 \mathrm{~m}$ resolution 619 sequentially-disaggregated and ground-measured soil moisture was 620 $0.062 \mathrm{vol}$. $/ \mathrm{vol}$. with a bias of $-0.045 \mathrm{vol}$. $/ \mathrm{vol}$. and soil moisture values 621 ranging from 0.08 to $0.40 \mathrm{vol}$. $/ \mathrm{vol}$. To assess the impact of the 622 intermediate resolution on disaggregation accuracy, a different 623 approach was proposed by setting the target resolution to $1 \mathrm{~km}$ and 624 by increasing the intermediate resolution from 3 to $12 \mathrm{~km}$. The 625 optimal intermediate resolution was found to be $3-5 \mathrm{~km}$, meaning 626 that the use of MODIS data reduced the non-linearity effects across 627 scales between SMOS and ASTER resolutions, despite the increase of 628 uncertainties associated with the combination of MODIS and ASTER 629 data.

Beyond the application of multi-resolution soil moisture data to a 631 range of environmental sciences, such an approach could greatly 632 facilitate the validation of coarse-scale microwave-derived soil 633 moisture data using point-scale ground measurements. The sequen- 634 tial model is being implemented over the Valencia Anchor Station area 635 (Lopez-Baeza et al., 2007) in the SMOS calibration/validation 636 framework.

Note that the operational application of thermal-based methods 638 would require high-spatial-resolution thermal data acquired at high- 639 temporal-resolution, typically 2-3 days. However, high-spatial-reso- 640 lution (ASTER-like) thermal data are currently available on a monthly 641 basis, which raises the issue of disaggregating low-spatial-resolution 642 (MODIS-like) thermal data at high-temporal-resolution (Agam et al., 643 2007).

Refinements of the sequential disaggregation method would 645 include a physical calibration of the soil evaporative efficiency 646 model, which is at present semi-empirical. Moreover, the disaggrega- 647 tion accuracy is affected by the non-linearity of that exponential 648 function. Recent developments have accounted for the non-linearity 649 of the models used in the disaggregation of remote sensing data with 650 the projection technique (Merlin et al., 2006) or the Taylor series 651 including derivative terms at orders superior to 1 citepmerlin08c. The 652 applicability of those approaches and their stability still need to be 653 confirmed at a range of spatial resolutions.

\section{Acknowledgements}

The NAFE'06 participants are gratefully acknowledged for their 656 participation in collecting this extensive data set. The National Airborne 657 Field Experiments have been made possible through infrastructure 658 (LE0453434 and LE0560930) and research (DP0557543) funding from 659 the Australian Research Council, and the collaboration of a large number 660 of scientists from throughout Australia, United States and Europe. Initial 661 setup and maintenance of the study catchments was funded by a 662 research grant (DP0343778) from the Australian Research Council and 663 by the CRC for Catchment Hydrology. This work was funded by the 664 French program Terre-Océan-Surface-Atmosphère and the Centre 665 National de la Recherche Scientifique. 


\section{References}

Agam, N., Kustas, W. P., Anderson, M. C., Li, F., \& Neale, C. M. U. (2007). A vegetation index based technique for spatial sharpening of thermal imagery. Remote Sensing of Environment, 107, 545-558.

Bindlish, R., \& Barros, A. P. (2002). Subpixel variability of remotely sensed soil moisture: An inter-comparison study of SAR and ESTAR. IEEE Transactions on Geoscience and Remote Sensing, 40, 326-337.

Chehbouni, A., Escadafal, R., Duchemin, B., Boulet, G., Simonneaux, V., Dedieu, G., Mougenot, B., Khabba, S., Kharrou, H., Maisongrande, P., Merlin, O., Chaponnière, A. Ezzahar, J., Er-Raki, S., Hoedjes, J., Hadria, R., Abourida, A., Cheggour, A., Raibi, F., Boudhar, A., Benhadj, I., Hanich, L., Benkaddour, A., Guemouria, N., Chehbouni, A. H., Lahrouni, A., Olioso, A., Jacob, F., Williams, D. G., \& Sobrino, J. A. (2008). An integrated modelling and remote sensing approach for hydrological study in arid and semi-arid regions: The SUDMED Programme. International Journal of Remote Sensing, 29(17), $5161-5181$.

Choudhury, B. J. (1994). Synergism of multispectral satellite observations for estimating regional land surface evaporation. Remote Sensing of Environment, 49(3), 264-274.

Crow, W. T., Ryu, D., \& Famiglietti, J. S. (2005). Upscaling of field-scale soil moisture measurements using distributed land surface modeling. Advances in Water Resources, 28(1), 1-14.

Das, N. N., \& Mohanty, B. P. (2008). Temporal dynamics of PSR-based soil moisture across spatial scales in an agricultural landscape during SMEX02: A wavelet approach. Remote Sensing of Environment, 112, 522-534.

Dubayah, R., Wood, E. F., \& Lavallee, D. (1997). Multiscaling analysis in distributed modeling and remote sensing: An application using soil moisture. In D. A. Quattrocchi, \& M. Goodchild (Eds.), Scale in Remote Sensing and GIS New York: Lewis Publisher.

Gillespie, A. R. (1985). Lithologic mapping of silicate rocks using TIMS. The TIMS Data User's Workshop (pp. 29-44). Pasadena, CA: JPL pub Vol. 86-38.

Kerr, Y. H., Waldteufel, P., Wigneron, J. -P., Martinuzzi, J. -M., Font, J., \& Berger, M. (2001). Soil moisture retrieval from space: The soil moisture and ocean salinity (SMOS) mission. IEEE Transactions on Geoscience and Remote Sensing, 39, 1729-1735.

Kim, G., \& Barros, A. P. (2002). Downscaling of remotely sensed soil moisture with a modified fractal interpolation method using contraction mapping and ancillary data. Remote Sensing of Environment, 83, 400-413.

Kim, G., \& Barros, A. P. (2002). Space-time characterization of soil moisture from passive microwave remotely sensed imagery and ancillary data. Remote Sensing of Environment, 81, 393-403.
Komatsu, T. S. (2003). Towards a robust phenomenological expression of evaporation 704 efficiency for unsaturated soil surfaces. Journal of Applied Meteorology, 42,1330-1334. 705

Liu, S., Mao, D., \& Jia, L. (2007). Evaluating parameterizations of aerodynamic resistance 706 to heat transfer using field measurements. Hydrology and Earth System Science, 11, 707 $769-783$.

Lopez-Baeza, E., Vidal, S., Cano, A., Domenech, C., Geraldo-Ferreira, A., Millan-Scheiding, 709 C., Narbon, C., Sanchis, J., \& Velazquez, A. (2007). Representativity of the Valencia 710 and the Alacant anchor stations in the context of validation of remote sensing 711 algorithms and low-resolution products. Proceedings of the Joint 2007 EUMETSAT 712 Meteorological Satellite Conference and the 15th Satellite Meteorology and Oceano- 713 graphy Conference of the American Meteorological Society. Amsterdam.

Merlin, O., Chehbouni, G., Kerr, Y., \& Goodrich, D. (2006). A downscaling method for 715 distributing surface soil moisture within a microwave pixel: Application to the 716 Monsoon'90 data. Remote Sensing of Environment, 101, 379-389. 717

Merlin, O., Walker, J. P. Chehbouni, A \& Kerr Y. (2008). Towards deterministic 718 downscaling of SMOS soil moisture using MODIS derived soil evaporative efficiency. 719 Remote Sensing of Environment, 112, 3935-3946. doi:10.1016/j.rse.2008.06.012. 720

Merlin, O., Walker, J. P., Kalma, J. D., Kim, E. J., Hacker, J., Panciera, R., Young, R., 72 Summerell, G., Hornbuckle, J., Hafeez, M., \& Jackson, T. J. (2008). The NAFE'06 data 722 set: Towards soil moisture retrieval at intermediate resolution. Advances in Water 723 Resources, 31, 1444-1455. doi:10.1016/j.advwatres.2008.01.018.

Merlin, O., Walker J. P. Panciera, R., Escorihuela, M. J. \& Jackson, T. J. (2009). Assessing 725 the SMOS soil moisture retrieval parameters with high-resolution NAFE'06 data. 726 Geoscience Remote Sensing Letters. doi:10.1109/LGRS.2008,2012727.

Realmuto, V. J. (1990). Separating the effects of temperature and emissivity: Emissivity 728 spectrum normalization. 2nd TIMS Workshop (pp. 310-316). Pasadena, CA: JPL pub 729 Vol. 90-55.

Rodriguez-Iturbe, I., Vogel, G. K., \& Rigon, R. (1995). On the spatial organization of soil 731 moisture fields. Geophysical Research Letters, 22(20), 2757-2760.

Thome, K., Palluconi, F., Takashima, T., \& Masuda, K. (1998). Atmospheric correction of 733 ASTER. IEEE Transactions on Geoscience and Remote Sensing, 36(4), 1199-1211. 734 doi:10.1109/36.701026. 735

Wan, Z. (2008). New refinements and validation of the MODIS land-surface temperature/ 736 emissivity products. Remote Sensing of Environment, 112(1), 59-74. doi:10.1016/j. 737 rse.2006.06.026.

Western, A. W., Grayson, R. B., \& Bloschl, G. (2002). Scaling of soil moisture. Annual 739 Review Earth Planetary Science, 30, 149-180.

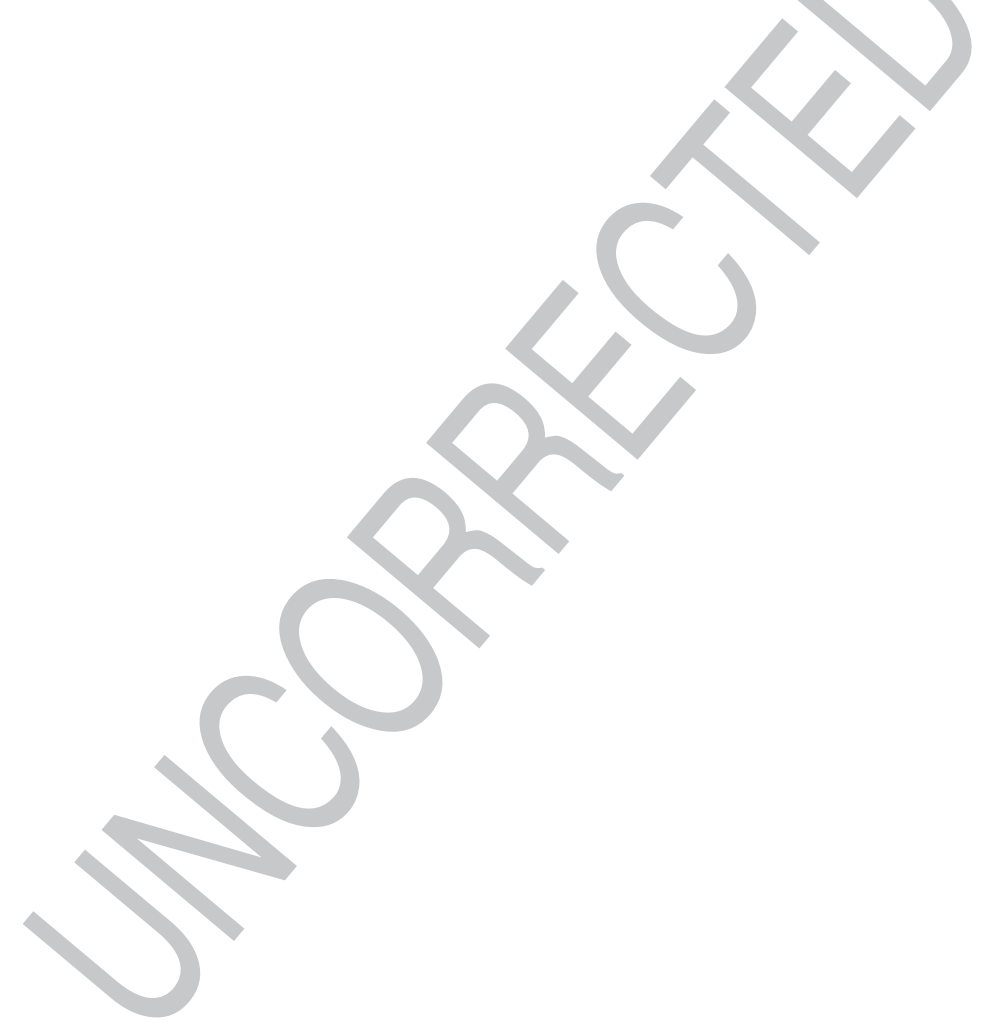

